\title{
Expanded roles of the Fanconi anemia pathway in preserving genomic stability
}

\author{
Younghoon Kee and Alan D. D'Andrea ${ }^{1}$ \\ Department of Radiation Oncology and Pediatric Oncology, Dana-Farber Cancer Institute, Harvard Medical School, Boston, \\ Massachusetts 02115, USA
}

Studying rare human genetic diseases often leads to a better understanding of normal cellular functions. Fanconi anemia (FA), for example, has elucidated a novel DNA repair mechanism required for maintaining genomic stability and preventing cancer. The FA pathway, an essential tumor-suppressive pathway, is required for protecting the human genome from a specific type of DNA damage; namely, DNA interstrand cross-links (ICLs). In this review, we discuss the recent progress in the study of the FA pathway, such as the identification of new FANCM-binding partners and the identification of RAD51C and FAN1 (Fanconi-associated nuclease 1) as new FA pathway-related proteins. We also focus on the role of the FA pathway as a potential regulator of DNA repair choices in response to double-strand breaks, and its novel functions during the mitotic phase of the cell cycle.

\section{The basic Fanconi anemia (FA) pathway}

FA is a genomic instability syndrome characterized by bone marrow failure, developmental abnormalities, and increased incidence of cancers ( $\mathrm{D}^{\prime}$ Andrea and Grompe 2003; Moldovan and D'Andrea 2009). At the cellular level, FA cells display increased chromosomal aberrations, particularly radials, and hypersensitivity to DNA interstrand cross-link (ICL) agents. DNA ICLs are among the most deleterious DNA lesions, since they block DNA replication and transcription. DNA ICLs can be caused by endogenous sources such as nitrous acid and aldehydes, or exogenous agents such as Cisplatin and its derivatives. Because of its essential functions in preserving genomic stability, the FA pathway provides a unique model for studying eukaryotic DNA repair and DNA damage responses, particularly against DNA ICLs.

FA is a genetically heterogeneous disease, caused by mutations in at least 13 distinct genes (FANCA, FANCB, FANCC, FANCD1, FANCD2, FANCE, FANCF, FANCG, FANCI, FANCI, FANCL, FANCM, and FANCN). All 13

[Keywords: Fanconi anemia; DNA repair; interstrand cross-link (ICL); homologous recombination (HR); nonhomologous end-joining (NHEJ); mitosis]

${ }^{1}$ Corresponding author.

E-MAIL alan_dandrea@dfci.harvard.edu; FAX (617) 632-5757.

Article is online at http://www.genesdev.org/cgi/doi/10.1101/gad.1955310. gene products are believed to function in a common DNA repair signaling pathway, the FA pathway, which closely cooperates with other DNA repair proteins for resolving DNA ICLs during replication (Fig. 1). A central event in the pathway is the monoubiquitination of FANCD2 and FANCI upon DNA damage, which is mediated by a group of upstream FA proteins (FANCA, FANCB, FANCC, FANCE, FANCF, FANCG, FANCL, and FANCM) that are assembled into a large nuclear E3 ubiquitin ligase complex, termed the "FA core complex" (Kennedy and D'Andrea 2005; Wang 2007). The monoubiquitinated FANCD2/FANCI heterodimer was shown to play multiple roles in the pathway (Knipscheer et al. 2009), and to functionally interact with downstream FA proteins such as FANCD1 (or BRCA2), FANCN, and FANCJ, and their associated protein, BRCA1. In addition to these core FA proteins, there are several FA pathway-associated proteins whose functions are critical to the pathway; however, mutations have not been found in the corresponding genes in FA patients. These include Fanconi-associated protein 24 (FAAP24), FAAP100, FANCM-associated histone fold protein 1 (MHF1), and MHF2 (Ciccia et al. 2007; Ling et al. 2007; Singh et al. 2010; Yan et al. 2010). All of these proteins are required for efficient activation of FANCD2 monoubiquitination. FAN1 (Fanconi-associated nuclease 1), the most recently identified FA-associated protein, was shown to provide the cryptic nuclease activity during the ICL repair (Kratz et al. 2010; Liu et al. 2010; Mackay et al. 2010; Smogorzewska et al. 2010). Although not required for FANCD2 monoubiquitination, it binds to the monoubiquitinated FANCD2 and mediates the critical downstream functions, possibly via restructuring the damaged DNA. The activated FA pathway must be inactivated for completion and recycling of the functional pathway, and this event is regulated by the USP1/UAF1 deubiquitinating enzyme complex, which deubiquitinates FANCD2 and FANCI (Nijman et al. 2005; Cohn et al. 2007; Smogorzewska et al. 2007). Disruption of the USP1/ UAF1 complex leads to elevated levels of FANCD2/ FANCI ubiquitination and DNA repair defects, suggesting a failure in the completion of the FA pathway.

In addition to these FA or FA-associated proteins, there are other DNA repair factors-specifically, DNA damage checkpoint proteins such as ATR, CHK1, and $\gamma-\mathrm{H} 2 \mathrm{AX}-$ that cooperate with the FA pathway in response to DNA 


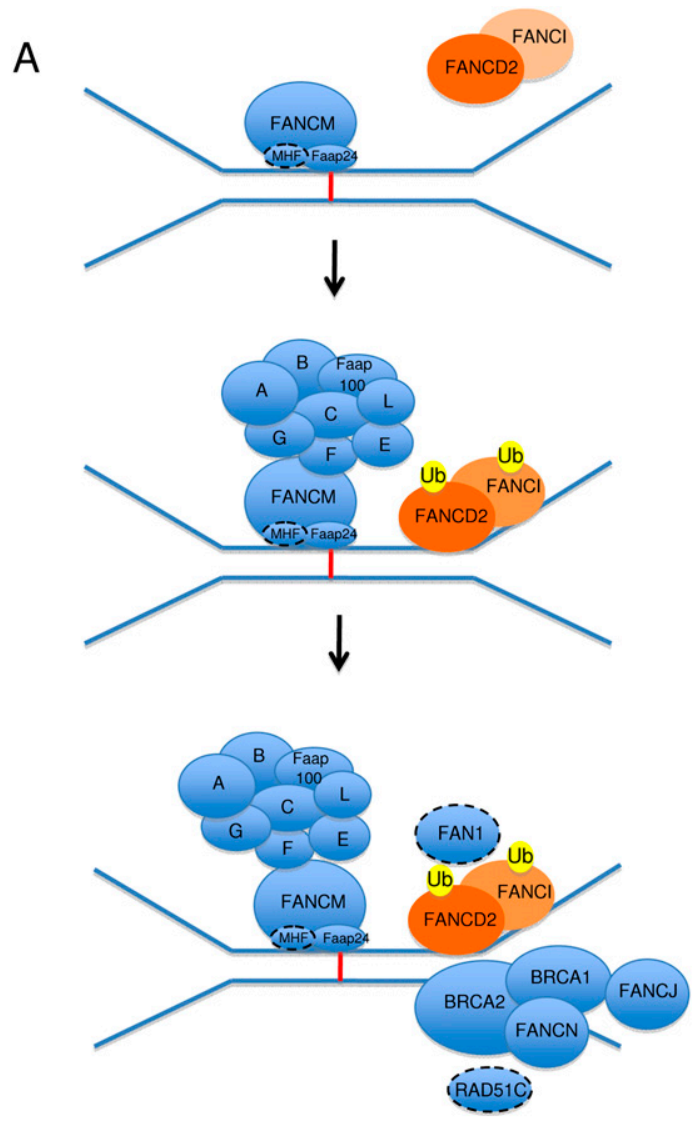

Loading of the FA core complex on chromatin induces monoubiquitination of FANCD2/FANCI.

Monoubiquitinated FANCD2/FANCI recruit FAN1 nuclease to the damages sites, and colocalize with

downstream FA proteins, possibly including

RAD51C, and facilitate DNA repair.
B

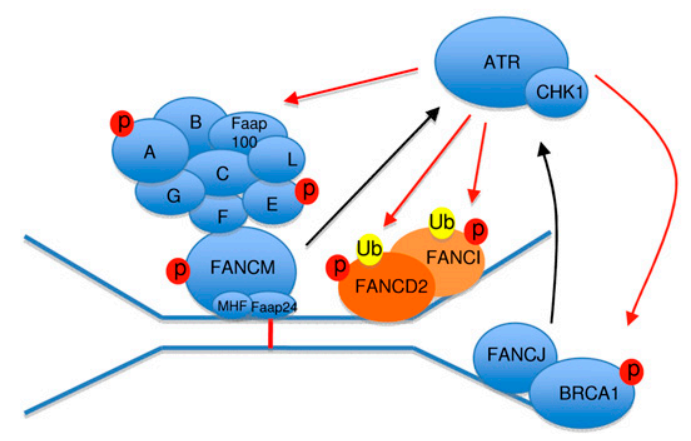

Figure 1. A schematic model for the FA pathway. (A) Activation of the FA pathway. DNA ICL is directly recognized by FANCM-FAAP24-MHF protein complex. This complex recruits the FA core complex by direct interaction between FANCM and FANCF. The recruited FA core complex, containing a PHD E3 ubiquitin ligase domain in the FANCL subunit, subsequently monoubiquitinates its two substrates, FANCD2 and FANCI, on chromatin. The monoubiquitinated FANCD2-FANCI becomes an active form, recruits newly identified nuclease FAN1 or interacts with a series of DNA repair proteins (including BRCA1, PALB2 [FANCN], BRCA2, and FANCJ [BACH1/BRIP1]) at the damaged sites, and facilitates downstream repair pathways. RAD51C, a newly identified FA-like protein, may have a functional interaction with FANCD2 at this step. FANCD2-FANCI probably also recruits other nucleases and TLS polymerases to process the ICL (not shown). The new players in the FA pathway described in the text are highlighted in dashed lines. (B) The FA pathway cross-talks with ATR-CHK1 checkpoint proteins. ATR and its effector kinase, $\mathrm{CHK} 1$, are required for damage-inducible activation of the FA pathway. ATR-CHK1 phosphorylates (red arrows) multiple FA and FA-associated proteins, including FANCA, FANCE, FANCD2, FANCI, and BRCA1. FANCM is also phosphorylated upon DNA damage by an unknown kinase. In turn, the stability and activity of ATR-CHK1 are promoted (black arrows) by the FANCM-FAAP24 heterodimer and FANCJ by independent mechanisms. FANCM also mediates the formation of the BRAFT complex, which contains the FA core complex members and the BLM complex containing Topo III $\alpha$ and RMI1/2 (not shown). damage (Andreassen et al. 2004; Wang 2007; Moldovan and D'Andrea 2009). These checkpoint proteins preserve genomic stability by arresting the cell cycle after DNA damage. Cells deficient in ATR kinase, a master regulator of S-phase checkpoint, are impaired in damage-inducible monoubiquitination of FANCD2, and are hypersensitive to ICLs (Andreassen et al. 2004). Many of the FA proteins are direct substrates of ATR or its effector kinase, CHK1-including FANCD2, FANCI, FANCA, and FANCE (Pichierri and Rosselli 2004; Smogorzewska et al. 2007; Wang et al. 2007; Ishiai et al. 2008; Collins et al. 2009/-and these phosphorylation events are required for a functional FA pathway and ICL repair. The FANCM and FAAP24 complex is also required upstream for efficient ATR-mediated checkpoint control (Collis et al. 2008; Luke-Glaser et al. 2010; Schwab et al. 2010).
Recently, FANCJ was also shown to regulate the ATRdependent checkpoint (Gong et al. 2010). Taken together, these studies suggest that the FA pathway is closely interconnected with other DNA damage response signals. The precise molecular function of individual FA proteins in repairing DNA and communicating with other DNA damage responses remains largely unknown. However, recent studies have provided unique insights to the field. These findings may potentially bring venues for novel therapeutic approaches for treating both FA patients and FA pathway-deficient tumors.

\section{FANCM plays multiple distinct roles during ICL repair}

While facilitating DNA cross-link repair, the FA pathway must coordinate other DNA damage-responsive events to 
stabilize stalled replication forks, to convey signals to DNA checkpoint pathways, and to facilitate recovery of replication forks. These events are largely coordinated by FANCM, a unique member of the FA pathway that plays distinct roles in checkpoint activation, chromatin remodeling, and ICL repair. FANCM contains a DEAH-type ATPase-dependent helicase domain, and it is one of the only two FA proteins with recognizable enzymatic activities, together with the helicase activity of FANCJ (Whitby 2010). FANCM is evolutionarily well conserved, as it is the only FA protein that has apparent orthologs in yeast (MPH1 in Saccharomyces cerevisiae, and Fmll in Schizosaccharomyces pombe) and archaebacteria (Hef) (Meetei et al. 2005; Sun et al. 2008). Also, FANCM is one of only two proteins in the human genome known to contain both a helicase/ATPase domain and an endonuclease domain in a single polypeptide, the other being ERCC4 (XPF) (Ali et al. 2009). The identity of FANCM as a bona fide FA protein is still in question, since the only known FANCMdeficient patient cell line, EUFA867, harbors an additional mutation in FANCA, and the full correction of the FA phenotype requires ectopic expression of both FANCM and FANCA (Singh et al. 2009). However, FANCM clearly plays critical roles in the FA pathway, and functions cooperatively with other FA core members. For instance, in DT40 cells, a double knockout of FANCM and FANCC exhibits ICL hypersensitivity similar to individual gene knockouts, indicating that FANCM and FANCC are epistatic (Mosedale et al. 2005). One role of FANCM in the FA pathway is to sense damaged DNA and recruit the FA core complex. FANCM was originally identified as a subunit of the FA core complex (Meetei et al. 2005), but its cellular distribution is distinct from the other FA core members. FANCM forms a heterodimeric complex with FAAP24, a protein sharing high similarity to the $\mathrm{C}$ terminus of FANCM and also containing an endonucleaselike domain (Ciccia et al. 2007). In vitro, the FANCM/ FAAP24 complex binds directly to DNA structures that resemble stalled replication forks. Also, the FANCM/ FAAP24 complex binds constitutively to chromatin, whereas other FA core proteins become enriched in the chromatin fraction only after DNA damage (Meetei et al. 2005; Mosedale et al. 2005; Kim et al. 2008). Furthermore, depletion of FANCM results in impaired localization of the FA core proteins. Taken together, these results suggest a model in which the FANCM/FAAP24 complex serves as a sensor that recognizes the DNA lesion and subsequently recruits the FA core complex to induce monoubiquitination of FANCD2/FANCI. However, cells from the FANCM knockout mice are still capable of inducing residual monoubiquitinated FANCD2 (Bakker et al. 2009). Accordingly, there may be a FANCM-independent recruiting mechanism for the FA core complex, or there may be a basal-level interaction between the FA core complex and FANCD2/I in the absence of FANCM/FAAP24.

FANCM also has unique features that are not shared by other FA core complex members. FANCM knockout mice display typical FA phenotypes (e.g., hypersensitivity to ICL, chromosomal breakage, and increased G2/M arrest), but also exhibit additional atypical phenotypes such as a low female ratio and increased cancer-related death (Bakker et al. 2009). FANCM-deficient cells are also hypersensitive to camptothecin, a topoisomerae I (Topo I) inhibitor that induces replication fork arrests, followed by DSB generation (Singh et al. 2009).

Unlike other FA subtypes, FANCM-deficient cells exhibit elevated frequency of sister chromatid exchange (SCE). Bloom's syndrome, a rare genetic disorder caused by a single mutation in the RecQ family helicase BLM, also exhibits elevated SCE, among other phenotypes that resemble FA, such as reduced fertility, genomic instability, and increased hematological cancers (Liu and West 2008). Interestingly, the overlapping phenotypes of FA and BLM could be linked molecularly to the ICL-induced assembly of a supercomplex, termed BRAFT (BLM, RPA [replication protein $\mathrm{A}], \mathrm{FA}$, and Topo $\mathrm{III} \alpha$ ), that contains the members of the FA core complex, BLM, and its associated proteins (Meetei et al. 2003). A recent study provided a direct demonstration that FANCM serves as an adapter between the FA proteins and the BLM complexes (Deans and West 2009|, and it was demonstrated that the elevated frequency of SCE is due to the failed assembly of the BRAFT through FANCM. Together, FANCM plays a critical role in mediating the cross-talk between the FA proteins and BLM complex, particularly in response to ICLs, and this could be the fundamental link for the overlapping clinical phenotypes between the two genetic disorders.

One of the FA-independent functions of FANCM is its ability to activate DNA damage checkpoints. FANCM and FAAP24, but not other FA proteins, were shown to associate physically with a complex containing ATRHCLK (HCLK2 is a stabilizer and signaling mediator of ATR), and thus are required for proper activation of the ATR-mediated S-phase checkpoints in response to replication stress (Collis et al. 2008). Depletion of FANCMFAAP24 leads to uninhibited cell cycle progression through G2/M phases. This function is dependent on its ATPase activity, which is dispensable for its monoubiquitination of FANCD2/FANCI, further suggesting the existence of at least two separate functions. One mechanism for ATR activation is the ability of FANCM to retain TOPBP1, a stimulator of ATR kinase activity, in the chromatin (Schwab et al. 2010). Although this checkpoint-activating function is not involved directly with the FA pathway, FANCM-mediated ATR activation may provide an indirect mechanism for further activating the FA pathway (see Fig. 1B). Also, more recent studies indicate that FANCM/FAAP24 can activate a specific ICL checkpoint response by enhancing RPA binding at the site of the ICL (AD D'Andrea, unpubl.).

In addition to checkpoint signaling, FANCM has a role in remodeling replication forks. In vitro, FANCM binds DNA structures that mimic replication forks and Holliday junctions, and moves the junction points through its branch migration activity in an ATPase-dependent manner (Gari et al. 2008b). This activity is also not coupled to the FA pathway, since the ATPase activity is dispensable for FANCD2/I monoubiquitination (Xue et al. 2008). A subsequent report showed that the fork migration activity leads to fork reversal during replication blockage, and suggested 
that this might be a mechanism for stabilizing forks during ICL repair, and limiting promiscuous recombination events (Gari et al. 2008a). Indeed, the ATPase activity was shown to be required for resistance to ICL agents (Xue et al. 2008). In vivo, FANCM-deficient cells showed uncontrolled replication fork movement and impaired fork restart during recovery from DNA damage (Luke-Glaser et al. 2010; Schwab et al. 2010), in line with FANCM's a role in remodeling forks during DNA repair. Taken together, FANCM may prevent undesired DNA synthesis during replication stress and DNA repair by coordinating checkpoint activation and remodeling DNA fork structures, while activating the FA pathway to facilitate ICL repair. FANCM-deficient cells are hypersensitive to various agents that inhibit replication fork progression (e.g., hydroxyurea $[\mathrm{HU}]$, aphidicolin $[\mathrm{APH}]$, and camptothecin) (Schwab et al. 2010) that are not seen in other FA-deficient cells, further suggesting that FANCM has wider roles in protecting stalled forks from mutagenic recombination and collapse.

Recent studies further demonstrate the complexity of FANCM function and regulation. These studies identified two histone fold proteins, named MHF1 and MHF2, as binding partners of FANCM (Singh et al. 2010; Yan et al. 2010). Both MHF1 and MHF2 appear to have coevolved with FANCM, as their orthologs exist from yeast to human (Yan et al. 2010). The new FANCM-associated proteins cooperate in both the FA pathway-dependent and independent functions of FANCM, as they are required for FANCD2 monoubiquitination, cross-linker repair, and branch migration-mediated fork reversal. The main function of MHF1-2 proteins appears to be stabilizing FANCM at the sites of ICL lesion (Yan et al. 2010). In addition, the epistatic relationship between the MHF and FANCM orthologs was observed in DT40 and yeast, suggesting their cooperation in a common pathway (Yan et al. 2010). Both MHF1 and MHF2 were shown previously to be identical to centromere-binding factor CENP-S and CENP-X, suggesting that they may also act to redirect FANCM to promote centromere stability (Yan et al. 2010)

Collectively, FANCM exerts multiple roles in preserving genome stability in response to DNA damage. Damaged DNA, especially ICL-modified DNA, can block the progression of replication forks. FANCM initially activates the S-phase checkpoint via its association with the ATR/CHK1/HCLK signaling complex to inhibit DNA replication. Next, FANCM recruits the FA core complex to the damaged chromatin and induces monoubiquitination of FANCD2/FANCI, thereby facilitating the processing of ICL repair, as illustrated in Figure 1. Finally, FANCM stabilizes the stalled replication forks by inhibiting reversal of the fork progression and limiting unwanted crossovers between sister chromatids.

\section{Broader roles of the FA pathway during ICL repair}

Repairing double-strand breaks (DSBs)_homologous recombination (HR) vs. nonhomologous end-joining (NHEJ)

The FA pathway plays a fundamental role in coordinating the repair of DNA DSBs. DSBs can be generated in numerous ways. Various genotoxic agents generate DSBs, including ionizing radiation (IR), chemicals that block DNA replication fork progression (such as $\mathrm{HU}$ ), or byproducts of cellular metabolism (such as reactive oxygen species (ROS)]. DSBs can also be generated as an intermediate of normal cellular processes during immunoglobulin class switching in immune cells. Failure to properly repair DSBs leads to chromosome translocations, genomic instability, and cell death or transformation. Cells have evolved two major specialized mechanisms to cope with these highly deleterious lesions; namely, HR and NHEJ.

Through HR, DNA sequences are exchanged between two similar or identical DNA strands. NHEJ is an alternative pathway in which two broken DSBs are sealed directly, without the need of homologous templates. Cells have evolved specialized proteins that facilitate either HR or NHEJ for DSB repair. Figure 2 describes the simple mechanistic models for HR and NHEJ, both pathways requiring multiple-step reactions. Because HR uses genetically identical complementary DNA strands as templates for repair, it is error-free, while NHEJ can be error-prone, since DNA end ligation can occur without preserving the correct frame of codons, resulting in loss of genetic information. Despite the higher risk of genomic instability, mammalian cells depend primarily on NHEJ, unlike in yeast, where HR is the primary choice for repairing DSBs.

\section{$D S B$ as an intermediate step in ICL repair}

In addition to the above-mentioned "direct" DSB-generating means, a DSB can also be generated as an intermediate of the ICL-repairing process (Fig. 3; Kennedy and D'Andrea 2005; Moldovan and D'Andrea 2009). In the current model, ICL hinders the progression of replication fork, which will activate checkpoints and monoubiquitination of FANCD2/FANCI, while the fork is stabilized by repair proteins. The cross-links are thought to be unhooked initially by serial activities of at least two endonucleases (XPF-ERCC1 and MUS81-EME1) (Niedernhofer et al. 2004; Hanada et al. 2006), and the lesion is subsequently bypassed by translesion synthesis (TLS) polymerases, which might be recruited by FANCD2 (Knipscheer et al. 2009; Moldovan and D'Andrea 2009). These processes would generate a DSB, which must be resolved properly for resumption of replication fork progression. The legitimate choice for DSB repair at this point would be HR, mainly because of availability of homologous templates. This hypothesis is strongly backed by reports that ablation of HR genes, but not NHEJ genes, leads to growth sensitivity toward ICL-inducing agents in various organisms (Cole 1973; Grossmann et al. 2001). Consistent with this notion is that $\mathrm{Ku}$ deletion chicken DT40 mutant cells are resistant to ICL agents compared with wild-type cells (Takata et al. 1998), and one interpretation could be that elevated HR would be beneficial for cells in repairing ICL. Below, we summarize and discuss the evidence that indicates HR is defective in FA cells, and how the FA pathway regulates resolution of the DSB intermediates during ICL repair. 


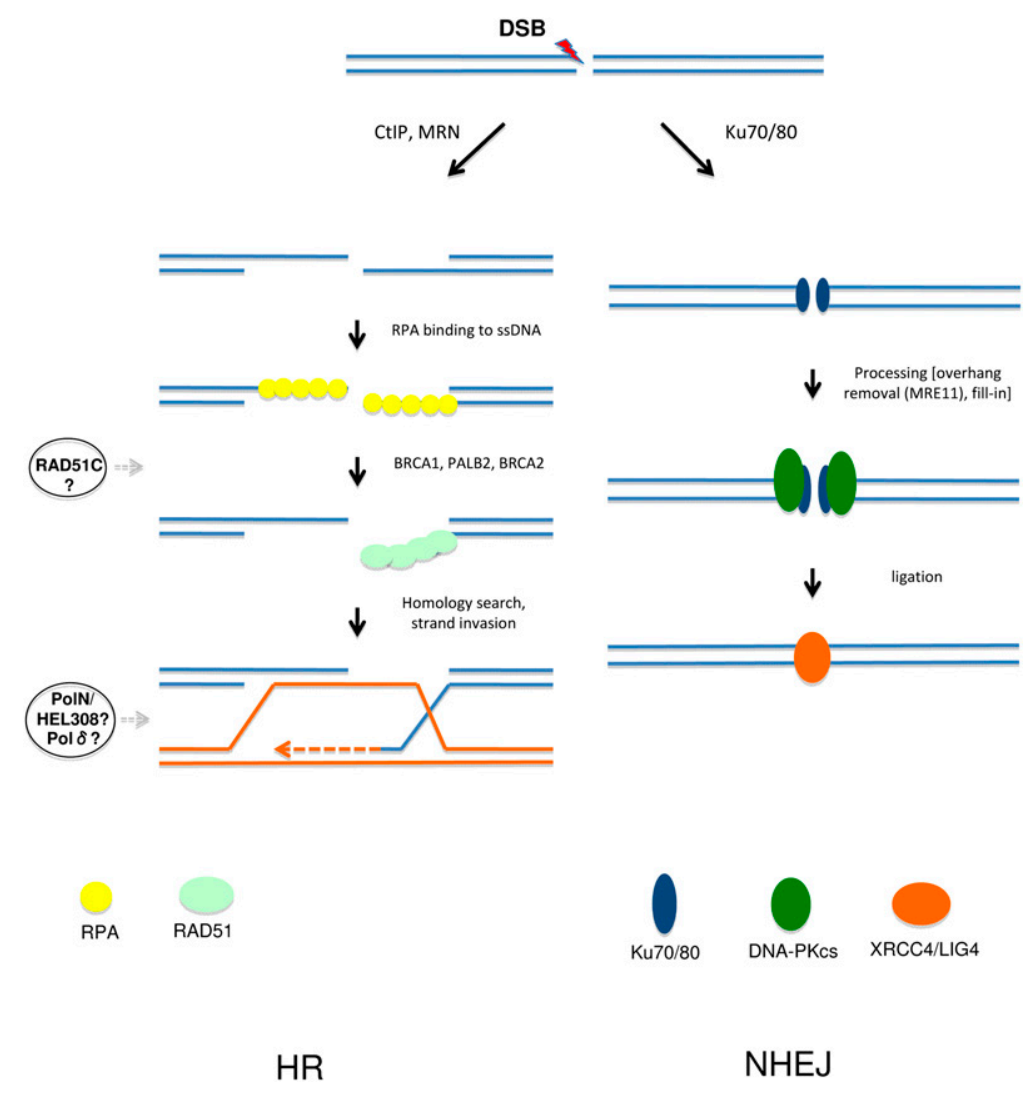

Figure 2. A schematic for DSB repair by HR and NHEJ pathways. DSBs can be repaired by either HR or NHEJ. New players (RAD51C and POLN/ HEL308) in the HR pathway are displayed in the left side of the figure, and are described in detail below. For initiation of HR, DSB ends must be resected to expose 3' overhangs of ssDNA by the exonuclease activity of CtIP. The exposed ssDNA is rapidly coated with RPA. RPA is then replaced by RAD51, the step facilitated by BRCA1, PALB2, and BRCA1. A mediator protein, RAD52, also helps RAD51 loading (not shown). The resulting ssDNARAD51 presynaptic filaments are capable of invading the homologous region in the nearby duplex DNA, forming a triplex DNA called a D-loop. DNA polymerases further extend DNA synthesis (possibly

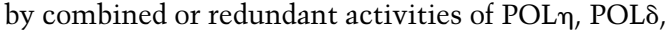
and POLN), and the recombination intermediates are finally resolved to complete the repair (not shown). RAD51C, one of the five RAD51 paralogs found in human cells, appears to promote loading of RAD51 (required for RAD51 foci formation) at an early step of HR. RAD51C-by forming a complex with another paralog, XRCC3-may also act to resolve Holliday junctions at the later step of HR (Liu et al. 2007). NHEJ directly seals two DSB ends and does not generally require DSB end resection. Binding of Ku70-80 heterodimer (the regulatory subunits of DNA-PK) at DSB ends recruits DNAPKcs. The activated DNA-PKcs recruits DNA ligase IV (LIG4), which subsequently joins two broken DNA ends. NHEJ can occur without homology, such as ligation between two blunt ends or ends with overhangs that can be processed by resection or fill-in. Recent studies suggested that the MRE11 nuclease may function in end processing (Zha et al. 2009) A minor form of NHEJ, microhomology-directed NHEJ, is not described here to keep simplicity. In addition to these "core" NHEJ proteins, other factors, such as MRE11 of the MRN complex, regulate certain types of NHEJ (Deng et al. 2009; Zha et al. 2009).

\section{Evidence for the FA pathway promoting $H R$}

Numerous studies have suggested that the FA pathway promotes HR repair. In DT40 cells, FANCG and FANCD2 knockout was shown to be defective in HR-mediated DSB repair and gene conversion at the IgG locus (Yamamoto et al. 2005). FANCC knockout DT40 cells are defective in $\mathrm{HR}$ and it is shown to be epistatic with $X R C C 2$, a RAD51 paralog, in sensitivity to ICL-inducing agents, suggesting that FANCC functions with XRCC in repairing DNA cross-links (Niedzwiedz et al. 2004). Most HR assays in mammalian cells were performed using a reporter-based system. In this system, site-specific DSBs are introduced by the restriction enzyme I-Sce1, resulting in the HRmediated generation of a functional GFP ORF. Repair by HR is scored as a positive GFP signal (Richardson et al. 1999). Using this system, it was shown that patientderived FANCA-, FANCG-, and FANCD2-deficient cells are defective, albeit to a mild degree, in HR repair (Nakanishi et al. 2005). Also, siRNA-mediated depletion of FANCI and FANCD2 resulted in reduced HR activities (Smogorzewska et al. 2007). Using an ICL-containing plasmid reporter system, it was further shown that depletion of FA genes, in addition to other DNA repair components, reduced HR activities (Zhang et al. 2007).
Consistent with these reports that the FA pathway promotes HR activities, a study using knockout mice did not show an epistatic relationship between FA and NHEJ in repairing DSBs, as FANCD2 ${ }^{-l-} / \mathrm{Prkdc}^{\mathrm{sc} / \mathrm{sc}}$ double-mutant mice (Prkd has reduced DNS-dependent protein kinase [DNA-PK] activity) are more sensitive to IR than Prkdc ${ }^{\text {sc/sc }}$ single-mutant mice (Houghtaling et al. 2005). USP1, the deubiquitinating enzyme required for deubiquitination of FANCD2/FANCI and completion of the FA pathway (Oestergaard et al. 2007; Smogorzewska et al. 2007; Kim et al. 2009), was also required for efficient HR activity, shown in a mouse knockout system (Kim et al. 2009), consistent with the reports that the FA promotes HR.

How the FA pathway promotes HR is unclear, but most evidence suggests that the monoubiquitination of FANCD2 is the critical regulatory event for promoting HR activity. The modified FANCD2 has been shown to recruit several DNA repair factors involved in HR (such as BRCA1, BRCA2, RAD51, and NBS1) to the damaged chromatin to facilitate repair (Garcia-Higuera et al. 2001; Nakanishi et al. 2002; Hussain et al. 2004; Wang et al. 2004; Zhi et al. 2009). Thus, deregulation of FANCD2 monoubiquitination in FA or USP1-deficient cells could directly result in the failure of recruitment of the DNA 


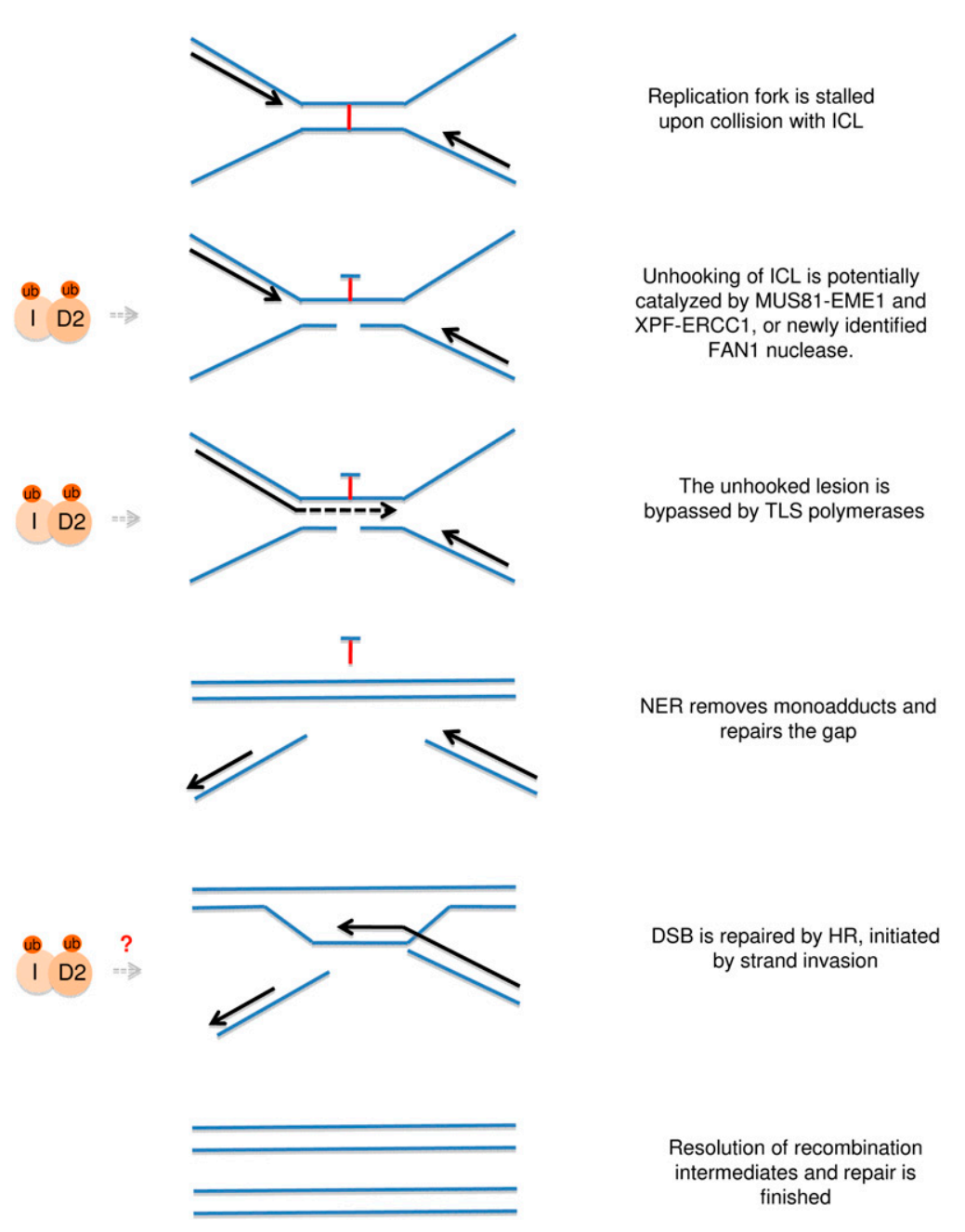

Figure 3. A simplified scheme for ICL repair. Progression of replication forks is blocked by ICL. The stalled replication forks can trigger multiple surveillance mechanisms, one of them being monobiquitination of the FANCD2/I heterodimer. The initial event is thought to be the incising of ICLs by serial or combined activities of XPF-ERCC1 and MUS81EME1. Potentially, the newly identified FAN1 might act on this step. These nucleases cut one side of the damaged DNA, unhooking the ICL and leaving a gap. The gap is subsequently bypassed by TLS polymerases, probably REV1, followed by removal of the monoadducts and repairing the gap. DSBs, a byproduct of the ICL repair process, are subsequently repaired by $\mathrm{HR}$ (see Fig. 2). Activated FANCD2/FANCI (brown circle) were shown to be required at multiple steps, including the nucleolytic incision and the TLS-mediated bypass (Knipscheer et al. 2009). Whether FANCD2/FANCI also functions directly in the HR process is unknown. repair factors to the DSB lesions, leading to defective initiation of the HR process.

Another line of evidence suggests that FANCD2 may also functionally cooperate with other DNA-metabolizing enzymes, possibly in the later step of HR. It was shown that DNA polymerase POLN and its associated helicase, HEL308, are required for HR activities and resistance to ICL-inducing agents (Moldovan et al. 2010). Notably, an epistatic relationship between POLN and FANCD2/ FANCI in HR was observed, and, consistently, a HEL308 and FANCD2 double knockout was similarly sensitive to ICL-inducing agents compared with single knockouts in Caenorhabditis elegans (Muzzini et al. 2008). Interestingly, C. elegans helq-1, an ortholog of HEL308, was shown to promote disassembly of postsynaptic RAD51 filament, a step required for completion of HR (Ward et al. 2010). Collectively, these results suggest a cooperative role of POLN/HEL308 and the FA pathway in promoting HR and ICL repair. In addition to POLN, the DNA synthesis step during HR appears to be mediated by other polymerases, as POL $\eta$ and POL $\delta$ were shown to be capable of synthesizing DNA from D-loop (displacement loop) recombination intermediates in vitro (McIlwraith et al. 2005; Li et al. 2009). These suggest that the multiple polymerases may participate cooperatively or redundantly in the completion of HR.

Last, it is tempting to speculate that there may be an indirect mechanism that contributes to decreased HR activity in FA cells. For instance, FA cells may have increased p53 activity, which in turn suppresses HR (Mekeel et al. 1997). Also, it cannot be ruled out that the "upstream" FA core complex (FANCA, FANCB, FANCC, FANCE, FANCF, FANCG, FANCL, and FANCM) proteins may have additional roles linked to the regulation of HR activity, but separate from their role in FANCD2/FANCI monoubiquitination.

\section{BRCA1, BRCA2, PALB2 (partner and localizer of BRCA2), and FANCJ}

More direct evidence for the participation of the FA pathway in HR came from the identification of BRCA2 as a FA subtype, FANCD1 (Howlett et al. 2002). BRCA2 is a critical factor required for initiating HR by directly binding and facilitating RAD51 loading onto ssDNA (Moynahan et al. 2001b; Litman et al. 2005). Subsequently, PALB2, a factor that binds and regulates localization of BRCA2 (Xia et al. 2006), was identified as a FA 
subtype, FANCN (Xia et al. 2007). BRCA1, a breast and ovarian cancer susceptibility gene, is not a FA gene per se, but it is closely linked to the FA pathway, as BRCA1deficienct cells also display cross-linker sensitivity, chromosomal breakage, and an HR defect (Moynahan et al. 2001a; Kennedy and D'Andrea 2005). A series of recent studies demonstrated critical interplays among BRCA1, BRCA2, and PALB2 in coordinating the HR process (Sy et al. 2009; Zhang et al. 2009a,b). It was shown that PALB2 also binds directly to BRCA1, thus bridging the interaction between BRCA1 and BRCA2. Importantly, BRCA1 mutations in patients that disrupt its interaction with PALB2 result in impaired HR and DNA damage response. Collectively, a model can be assembled in which BRCA1 acts to recruit PALB2, which in turn recruits BRCA2 onto ssDNA. FANCJ (also known as BACH1 [BRCA1-associated C-terminal helicase] or BRIP1 [BRCA1-interacting protein C-terminal helicase 1]) is also mutated in hereditary breast cancer, and is required for HR (Bridge et al. 2005; Levitus et al. 2005; Levran et al. 2005; Litman et al. 2005). Genetic analyses in C. elegans suggested that $\log -1$, a FANCJ ortholog, is epistatic with FANCD2 in ICL repair, suggesting that FANCJ functions cooperatively with FANCD2, although FANCJ was suggested to work downstream from RAD51, unlike FANCD2 (Youds et al. 2008). Interestingly, it was also shown that FANCJ is not epistatic with BRC-2, the $C$. elegans BRCA1, in ICL repair, suggesting that FANCJ participates in two distinct pathways. This observation is consistent with reports that the FANCJ-BRCA1 interaction is not required for HR and ICL repair (Bridge et al. 2005; Peng et al. 2007). How FANCJ functions mechanistically in HR is unclear, although it was suggested to function in limiting promiscuous recombination filament intermediates (Sommers et al. 2009).

A well-known feature that distinguishes BRCA1, BRCA2 (FANCD1), PALB2 (FANCN), and BACH1 (FANCJ) from other FA proteins is that these proteins are not required for monoubiquitination of FANCD2. In addition, these factors are more strictly required for HR activity compared with the rest of the FA proteins. The fact that germline mutations in these genes increase the risk of breast and ovarian cancers (Wooster and Weber 2003; Turnbull and Rahman 2008) suggests that HRmediated DNA repair is a critical tumor-suppressive mechanism lacking in these and other cancers.

Altogether, there seem to be multiple mechanisms by which the FA pathway promotes the HR pathway. Precisely how these multiple events converge in a coordinated manner for promotion of HR is an important future topic. For instance, how can one link the HR-deficient phenotypes seen in FA cells (e.g., FANCA) to the "downstream" FANCD1/BRCA2 phenotypes? Is the monoubiquitinated FANCD2 a critical link between the "upstream" FA proteins and downstream factors such as BRCA2 or PALB2? At least one report showed that BRCA2 interacts physically with FANCG, and that they are epistatic in cross-linker sensitivity (Wilson et al. 2008). But why are the upstream FA mutant cells only modestly deficient in HR compared with the cells mu- tated in core HR genes? It is possible that the FA proteins preferentially regulate a "sub-HR" pathway that is dedicated to resolving ICL damage. Along these lines, BRCA2 may be engaged in a wider range of DSB repairs, including the ICL repair and other repairs.

\section{Familial mutations of RAD51C identified in FA-like patients}

Identification of the 13 FA genes has provided hints that a major function of the FA pathway is to regulate HR activities during ICL repair. There are still some FA patients with unassigned FA subtypes, and identification of additional FA genes will provide further insights into the molecular functions of the FA pathway. Two recent studies indeed provide such insights. One study reported the identification of RAD51C-a member of the RAD51like family that is essential for RAD51-mediated HR-as a causative gene biallelically mutated in a family with "FA-like" phenotypes (Vaz et al. 2010). An accompanying study further reported identification of monoallelic (heterozygous) germline mutations in RAD51C genes resulting in an increased incidence of breast and ovarian cancers (Meindl et al. 2010). These two reports reaffirm the close genetic relationship between FA and breast cancer susceptibility (Levy-Lahad 2010). Among the three affected children from the family with the RAD51C homozygous mutation, two siblings died at a very young age, with multiple congenital abnormalities and elevated chromosomal breakages in lymphocytes upon exposure to ICL, strongly suggesting FA. The only surviving patient exhibited many characteristic FA phenotypes, such as ICL-induced chromosomal breakage, congenital abnormalities (short stature), and pronounced cell cycle arrest at $\mathrm{G} 2 / \mathrm{M}$, and the cellular phenotypes were rescued by exogenous RAD51C cDNA expression (Vaz et al. 2010). These results suggest that $R A D 51 C$ could be the 14 th FA complementation group (FANCO). However, the assignment was tentative, since there was only a single family reported so far, and the only surviving patient, at the age of 10, did not show the hematological abnormalities and/or cancers commonly observed in FA patients. However, as Vaz et al. (2010) noted, the age of onset of these phenotypes among FA patients varies. Therefore, a "provisional" assignment of FANCO was given, subject to confirmation with additional families with the mutation (C Mathew, pers comm.).

These reports put $R A D 51 C$ in the list of cancer susceptibility genes that are classified as classic FA-associated HR genes, including BRCA1, BRCA2 (FANCD1), PALB2 (FANCN), and BACH1 (FANCJ) (Turnbull and Rahman 2008; Levy-Lahad 2010; Meindl et al. 2010). Whether RAD51C has direct functional relationships with FA proteins remains unclear. RAD51C appears to have multiple roles in $\mathrm{HR}$, as it is required for RAD51 foci, suggestive of an upstream function, and for resolving Holliday junction intermediates at a later step of HR (Takata et al. 2001; French et al. 2002; Liu et al. 2004, 2007; Rodrigue et al. 2006). The latter function remains controversial, given the recent identification of GEN1 as 
the true resolvase responsible for resolution of Holliday junction (Ip et al. 2008). RAD51C contains a functional NLS (nuclear localization signal) at the $\mathrm{C}$ terminus, and it was suggested to play a role in nuclear transport of RAD51 following DNA damage (French et al. 2002; Gildemeister et al. 2009). In agreement with this, overexpression of RAD51 partially rescued the Cisplatin sensitivity of RAD51C mutant DT40 cells, suggesting that at least partial function of RAD51C is to promote RAD51 activity during HR (Takata et al. 2001). How RAD51C promotes RAD51 foci formation and HR activity is unknown, although one report indicates that binding of RAD51C to RAD18, a RING domain E3 ubiquitin ligase involved in PCNA monoubiquitination, is required for RAD51 foci and HR activity (Huang et al. 2009).

As different FA proteins are involved in these steps as well, RAD51C may communicate with multiple FA proteins at different steps for promoting HR. Also, as there are other known paralogs of RAD51 (RAD51B, RAD51D, XRCC2, and XRCC3) that are all critical for HR activity, ICL resistance, and genomic stability (Takata et al. 2000; Thompson and Schild 2001; Rodrigue et al. 2006), it is possible that mutation of these genes might be responsible for other unassigned FA subtypes. Altogether, these reports further emphasize the importance of the FA pathway in regulating HR.

\section{Choice between HR and NHEJ}

How cells choose one pathway or the other during DSB repair remains poorly understood. The key determinant for the selectivity between the two pathways appears to be the availability of sister chromatids. When DSBs occur during replication fork arrest, the easy accessibility of a homologous template makes HR the best choice. Thus, HR is believed to act primarily on "replication-associated" DSBs. However, random DNA-damaging events, such as chemical modification of DNA (e.g., caused by IR), may occur even when chromatin is in a compact stage, such as during G1 phase of the cell cycle. NHEJ may be an easier and efficient choice in the latter case, where homologous DNA is not necessarily accessible. Accordingly, it is reasonable for cells to depend heavily on HR during $S$ or G2 phases, when the homologous template or sister chromatids are present nearby, while using NHEJ during G1 phases. An experiment using the DT40 system supported this hypothesis by showing that ku70 mutants are extremely sensitive to IR when cells are synchronized in G1, and recover in S/G2 phases, while rad54 mutants are selectively sensitive in S/G2 phases (Takata et al. 1998). There may be multiple mechanisms to regulate differential usage during the cell cycle.

Although one decisive factor for differential usage may be the availability of sister chromatids, increasing evidence suggests that there may be competition between the two pathways (Pierce et al. 2001; Karathanasis and Wilson 2002; Branzei and Foiani 2008; Yun and Hiom 2009). A major mechanism appears to be governed by CDK1-mediated phosphorylation of CtIP (Sae2 in yeast) in S phase. This event activates the nuclease in DNA end resection, thus facilitating ssDNA formation and the initiation of HR (Sartori et al. 2007; Huertas et al. 2008). CtIP phosphorylation in S phase was also shown to be essential for BRCA1 recruitment and HR activities (Yu and Chen 2004; Yun and Hiom 2009). Thus, recognition of DSB ends by CtIP may be a decision point at which the HR pathway is preferred over NHEJ. Although it is not known whether an absence of CtIP phosphorylation leads to increased NHEJ activity in S phase, NHEJ activity does appear to persist throughout the cell cycle (Takata et al. 1998; Kim et al. 2005), further supporting the hypothesis of the existence of interpathway competition. However, certain mechanisms might also exist to actively downregulate NHEJ activity during S phases (Lee et al. 1997; Chen et al. 2005). A series of recent studies led by Nussenzweig and coworkers (Cao et al. 2009; Bunting et al. 2010) further supports this "competition" hypothesis by demonstrating that the interplay between BRCA1 and 53BP1 may mediate a pathway choice between HR and NHEJ. 53BP1 is an ATM substrate involved in DNA damage checkpoints, and it is required for facilitating certain types of NHEJ processes (DiTullio et al. 2002; Difilippantonio et al. 2008). These studies elegantly showed that an underlying mechanism for elevated genomic instability in BRCA1-deficient cells is the overuse of NHEJ for DSB repair. A critical NHEJ-promoting event is the inhibition of CtIP-mediated DNA end resection by 53BP1. Deletion of 53BP1 restored RAD51 foci and genomic stability in BRCA1-deficient cells. Deletion of LIG4, the end-joining ligase that functions downstream in NHEJ, did not rescue the phenotype, while it still inhibited end-joining, reaffirming the notion that 53BP1 binding is the determinant of the HR inhibitory event. Interestingly, in a more recent independent study, a 53BP1 mutation was found to be a suppressor of proliferation-deficient and ICL-sensitive phenotypes of BRCA1-null cells in a transposon-mediated genetic screen (Bouwman et al. 2010). It was shown that 53BP1 depletion restores HR activity (RAD51 foci), decreases the amount of chromosome breakages in BRCA1-null cells, and abrogates the ATM-mediated DNA damage checkpoint. The decreased DNA checkpoint activity may be due to restored HR and efficient DNA repair activities. Furthermore, Bouwman et al. (2010) found a strong correlation between reduced levels of 53BP1 and more aggressive triple-negative (estrogen, progesterone, and HER2 receptor-negative) breast tumors. This suggests that having a secondary mutation in 53BP1 might be a compensatory mechanism for the BRCA1-deficient tumors to be drug-resistant.

Although the above studies focus only on BRCA1deficient settings, the role of 53BP1 in promoting NHEJ may be more widespread (Difilippantonio et al. 2008; Dimitrova et al. 2008). Together, these studies suggest that the displacement of 53BP1 by BRCA1 provides a key DNA repair pathway choice, favoring HR. Interestingly, BRCA1 binding to DSB ends also provides a mechanism for inhibiting the exonuclease activity of MRE11, a subunit of MRN complex (Paull et al. 2001). The MRE11 
exonulcase activity was shown to be required for both HR and NHEJ (Zha et al. 2009). Thus, BRCA1 may also promote HR by specifically inhibiting the MRE11-mediated DSB end processing event required for NHEJ. These findings further suggest that there may be broader mechanisms that regulate the dynamic competition between HR and NHEJ factors at the site of DSB lesions. Very recent studies indicate that FA proteins may have similar functions at the site of DSBs during ICL repair.

\section{The FA pathway suppresses NHEJ and promotes $H R$}

While multiple mechanisms exist to ensure selective activation of HR in S phases, how this might be achieved during ICL repair is unknown. Since FA-deficient cells are only mildly sensitive to DSB-inducing agents (e.g., IR and $\mathrm{HU}$ ), the FA pathway is specialized, at least in part, in the regulation of HR activities, specifically during ICL repair. As described above, monoubiquitinated FANCD2-mediated recruitment of $\mathrm{HR}$ factors (e.g., BRCA1 and BRCA2) may be one mechanism of promoting HR during ICL repair. Whether the FA pathway also suppresses NHEJ has not been explored until recently. A series of recent studies-using a combination of C. elegans, chicken DT40, and mammalian cell studies-has provided provocative evidence that the FA pathway is indeed involved in the active suppression of the NHEJ pathway (Adamo et al. 2010; Pace et al. 2010). In the former study, the FA phenotypes (e.g., ICL sensitivity, chromosomal breakages, and developmental abnormality) of $f c d-2$ worms and mammalian FA-deficient cells (FANCD2, FANCA, and $F A N C C$ ) were all, at least in part, rescued by inhibition of the NHEJ pathway, while, in the latter study, ICL sensitivity and HR defect of the FANCC knockout DT40 cells were partially rescued by additional Ku70 knockout. (The discrepancy here is that the latter study did not observe the suppressive effects by knocking out DNA-PK catalytic subunit [DNA-PKcs] or Lig4, other downstream NHEJ factors.) These results suggest that the FA phenotypes arise not simply due to a weakness in HR, but also to a failure in NHEJ suppression. Although the underlying molecular mechanism remains to be identified, several different scenarios are possible. Loss of the FA pathway may result in impaired recruitment of NHEJsuppressive factors such as PARP-1 and RAD18 (Saberi et al. 2007), leading to a heightened NHEJ activity. Alternatively, loss of the FA pathway may result in impaired recruitment of early HR factors at DSB sites that might be coupled to the impaired displacement of NHEJ factors from the lesion. Indeed, inappropriate recruitment of DNA-PKcs at the site of DSBs was observed in the FANCD2-deficient cells (Adamo et al. 2010). FANCD2 might also have a cryptic role in blocking the recruitment of NHEJ factors to the site of DSBs, as purified FANCD2 was shown to possess an intrinsic exonuclease activity in vitro (Pace et al. 2010) that might generate specific DNA structures that exclude binding of NHEJ factors. Polyubiquitination and degradation of Ku80 on chromatin is a possible mechanism for its release from chromatin (Postow et al. 2008), and the FA pathway may be required.
Either model would be consistent with the observation that more active DNA-PK proteins are associated with damaged chromatin in FA-deficient cells. It appears that the nonfunctional FA pathway may render NHEJ the "default" pathway, leading to more error-prone DNA repair and the accumulation of insertions and deletions. It is interesting to speculate that a hidden function of monoubiquitinated FANCD2/FANCI complex might be facilitating removal of NHEJ factors (e.g., Ku70/80) from damaged chromatin, thus suppressing the downstream end-joining process. This would be similar to the mechanism observed in BRCA1 and 53BP1 studies (Bouwman et al. 2010; Bunting et al. 2010). It is noteworthy that inhibition of LIG4 rescued the FA phenotype, but did not rescue the BRCA1 deficiency (Bunting et al. 2010), potentially suggesting that the FA pathway might be involved in inhibiting both initiation and downstream end-joining steps of the NHEJ pathway. Figure 4 describes the hypothetical mechanisms for suppressing NHEJ during general and ICL-mediated DSB repair processes.

What is the implication for the clinical treatment of FA? Hyperactivation of error-prone NHEJ during ICL repair may elevate the undesirable increase in mutagenesis and random end-joining between neighboring broken

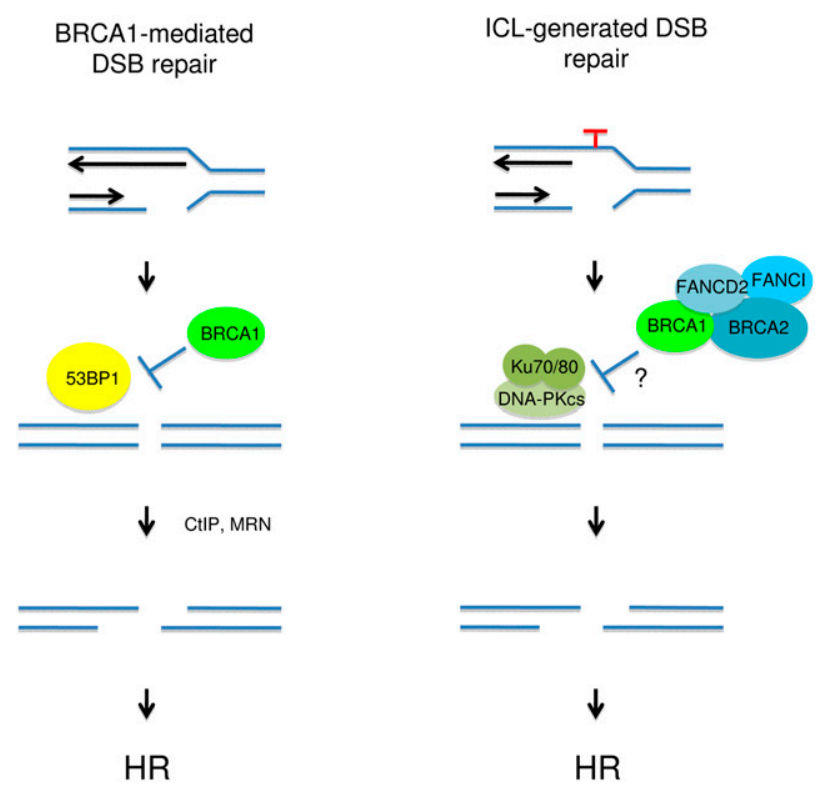

Figure 4. A hypothetical model for NHEJ-suppressive mechanisms during DSB repair. For repairing "replication-associated" DSBs, multiple mechanisms can be employed to promote HR. (Left panel) BRCA1 may have a function to displace 53BP1 from DSB ends, allowing ATM-CtIP-dependent DNA end resection and initiation of HR. In BRCA1-deficient cells, sustained activity of 53BP1 at DSB ends may inhibit the end resection, while it facilitates recruitment of NHEJ factors. (Right panel) FA proteins (FANCD2, FANCI, BRCA2, PALB2, or BRCA1) may have roles in precluding NHEJ factors (e.g., Ku70/80 and DNA-PKcs) from binding to DSB ends by either direct inhibition or facilitating HR initiating events, such as DNA end resection. Deletion or pharmacological inhibition of the NHEJ pathway rescues FA-deficient phenotypes. 
chromosomes (Newell et al. 2004). Likewise, improper usage of NHEJ during the hematopoietic program, where HR plays a more critical role, may result in genomic instability, leading to bone marrow failure. These studies also suggest that usage of DNA-PK inhibitors may be beneficial for treating both FA patients and FA-associated tumors, although there may also be a risk of enhanced toxicity for FA patients treated with the drugs. Further investigation of the potential therapeutic approach may have a significant impact on the treatment of FA patients.

\section{Identification of FAN1}

Although the key molecular event in the FA pathway is the generation of monoubiquitinated FANCD2/FANCI, the exact molecular functions of the modified FANCD2/ FANCI proteins remain enigmatic. Four recent studies (Liu et al. 2010; Kratz et al. 2010; Mackay et al. 2010; Smogorzewska et al. 2010) describe at least one novel function of monoubiquitinated FANCD2. They showed that FAN1 (previously known as KIAA1018), a novel nuclease with a $\mathrm{N}$ terminus UBZ (ubiquitin zinc finger) domain and a $\mathrm{C}$ terminus nuclease domain, associates with monoubiquitinated FANCD2. The initial identification of FAN1 as a FA-like factor came from different approaches, as it was identified from a genome-wide shRNA screen searching for ICL sensitizer (Smogorzewska et al. 2010), as a binding partner of FANCD2 (Liu et al. 2010), as a binding partner of MLH1 mismatch repair protein (Kratz et al. 2010), and through a bioinformatic search for the UBZ and nuclease domain-containing proteins (Mackay et al. 2010). The groups collectively found that FAN1 (1) possesses a nuclease activity that is required for cellular resistance against ICL agents, (2) is recruited to damaged DNA via its UBZ domain and monoubiquitinated FANCD2, and (3) associates rather specifically with monoubiquitinated FANCD2. As discussed throughout this review, one important function of monoubiquitinated FANCD2 is the promotion of HR. Indeed, depletion of FAN1 resulted in reduced HR efficiency in human cells (Mackay et al. 2010), although the formation of RAD51 or RPA foci was not affected, suggesting that FAN1 might have a role downstream in the HR process.

Collectively, a model can be assembled that FAN1 is recruited to the damaged sites via specific interaction between the UBZ domain of FAN1 and monoubiquitinated FANCD2, followed by the nucleolytic cleavage of DNA (potentially near ICL), which is necessary for subsequent ICL repair. Exactly at which step FAN1 acts to promote ICL repair remains unknown. However, as the Walter laboratory (Knipscheer et al. 2009) demonstrated using Xenopus extracts, monoubiquitinated FANCD2 is required for the nucleolytic incision and unhooking of the ICL. An intriguing question is whether FAN1 represents the cryptic nuclease activity observed in the in vitro system. However, as there are several other nucleases proposed to act during ICL (such as the MUS81-EME1, XPF-ERCC1, SLX4 complex, and the FANCD2 nuclease itself) (Niedernhofer et al. 2005; Knipscheer et al. 2009;
Moldovan and D'Andrea 2009; Pace et al. 2010), the exact functions of each nuclease in promoting ICL repair is yet to be elucidated.

\section{Expanded roles of the FA pathway in mitosis}

DNA damage often occurs spontaneously during DNA synthesis, resulting in nucleotide misincorporations, insertions, and deletions (Branzei and Foiani 2008). Many DNA repair events are believed to predominate during $S$ phase. HR repair can also occur in G2 phase, and it may therefore prevent the passage of unrepaired mutations to daughter cells in mitosis (Branzei and Foiani 2008). Whether DNA repair machineries remain active during mitosis is unclear, and the higher-ordered chromatin compaction of mitosis may prevent access of the repair machineries. To date, most studies of FA proteins have focused on their role in regulating DNA repair mechanisms during $\mathrm{S}$ phases.

A series of recent studies has provided exciting new evidence that the FA pathway has roles during mitosis. Specifically, the pathway can serve as a surveillance mechanism to monitor unrepaired DNA (Chan et al. 2009; Naim and Rosselli 2009a). Fragile sites, regions in the chromosome that represent incomplete DNA replication, such as gaps, are known to be caused spontaneously or by treating cells with drugs causing replicative stress (e.g., APH). FA-deficient cells exhibit increased chromosomal breaks at fragile sites, and this high incidence may be linked to high cancer rates in FA patients (Porfirio et al. 1991; Fundia et al. 1994; Howlett et al. 2005). These early studies suggested that the FA pathway has a role in regulating the generation and frequency of unstable regions in the chromatin. However, the mechanistic link between the FA pathway and the abnormal chromosomal regions was unclear. Interestingly, the Hickson and Rosselli groups (Chan et al. 2009; Naim and Rosselli 2009a) have demonstrated that APH treatment in cells induces the increased staining of FANCD2 foci in fragile sites within the compact mitotic chromosomes. Furthermore, the lack of FANCD2 staining in FAdeficient cells (which also suggested that they are likely to be monoubiquitinated forms of FANCD2) strongly correlated with generation of elevated micronuclei in daughter cells. Interestingly, the location of FANCD2 (and FANCI) spots reside in the extremities of mitotic DNA structures, termed ultrafine DNA bridges (UFB) (Chan et al. 2007), which are shown to connect the common fragile sites between sister chromosomes. Thus, a hypothesis is that the presence of FANCD2/FANCI on the fragile sites may be a surveillance mechanism to mark the incomplete replication that escaped the $S$ or G2 checkpoint, and certain mechanisms might exist during mitosis to repair such lesions (Chan and Hickson 2009).

The molecular function of FANCD2/FANCI in the unstable region remains unclear, but it appears to be related, at least partially, to the recruitment and stabilization of BLM protein on the bridges (Naim and Rosselli 2009a). Accordingly, FA-deficient cells have decreased BLM localization on the bridges. BLM is a RecQ helicase 
mutated in Bloom's syndrome that is also characterized by increased sensitivity to ICL and predisposition to cancer. BLM forms a large complex containing the FA core complex proteins (Meetei et al. 2003), and the interaction between BLM and FANCM was shown to be critical for mediating cellular resistance to ICL (Deans and West 2009). The exact function of BLM on the UFB is unknown, although it was suggested to promote unwinding and decatenation of UFBs for proper segregation of sister chromatids. Interestingly, BLM-deficient cells also exhibit increased bridges and micronuclei in daughter cells (Chan et al. 2007). Altogether, it seems that FA proteins are required for recruiting BLM to the bridges to facilitate stabilization and resolution of the unresolved chromatin, preventing aberrant cytokinesis and micronuclei formation.

Collectively, these data suggest that unresolved DNA damage during S/G2 phases persists to mitosis, and one function of the FA pathway is to recognize the fragile sites to prevent aneuploidy and chromosomal instability. Interestingly, other DNA repair proteins that associate with the FA pathway-such as BRCA1, RAD51, and ATR-are also known to regulate the stability of fragile sites (Casper et al. 2002; Arlt et al. 2004; Naim and Rosselli 2009b). Furthermore, BRCA2-deficient cells were shown to exhibit aberrant chromosomal segregation leading to aneuploidy (altered chromosome number) (Daniels et al. 2004). It will be interesting to investigate whether there are functional interactions with these proteins with the FA pathway during mitosis to prevent chromosomal instability.

\section{Concluding remarks and future considerations}

Since the first discovery of the FANCC gene (Strathdee et al. 1992), there have been significant advances in the fields of molecular biology and pathogenesis of FA. Identification of RAD51C as a potential new FA gene reaffirms $\mathrm{HR}$ as a key DNA repair mechanism regulated by the FA pathway. Identification of FAN1 as an effector molecule of monoubiquitinated FANCD2 led us one step closer to understanding the elusive role of the FANCD2 modification. Further elucidation of how FANCD2/ FANCI, FAN1, and the downstream FA proteins including RAD51C coordinate the whole ICL repair process is not far from reach.

The observation that inhibiting NHEJ partially rescues the cellular FA phenotypes provides an exciting opportunity for developing strategies for treating FA-related diseases. Further characterization of this mechanism will solidify the notion that deregulation of repair choice between HR and NHEJ is the key step missing in FAdeficient cells.

Until recently, the FA pathway was thought to be largely inactivated during mitosis, due to the absence of monoubiquitinated FANCD2, as determined by Western blots (Taniguchi et al. 2002). Accordingly, mitotic phosphorylation and degradation of FANCM, which leads to the release of the FA core complex, may be one mechanism for inactivating the FANCD2 monoubiquitination during mitosis (Kim et al. 2008; Kee et al. 2009). However, the clear presence of activated FANCD2/FANCI on the fragile sites of mitotic chromosomes suggests that the FA pathway is still functional during mitosis. Further investigation of the role of FA proteins during mitosis will shed light on other hidden functions of the FA pathway in preserving genomic stability, and potentially provide a novel therapeutic approach for treating FA. Furthermore, it will be important to investigate whether the failure of the hematopoietic program in FA bone marrow cells are linked to the aberrant mitotic phenotypes observed in FA cells.

Another interesting question to address mechanistically is why FA cells are particularly sensitive to ICL, but not to other DNA-damaging agents such as IR or HU. As evidence suggests that the FANCM/FAAP24/MHF complex may directly recognize cross-linked DNA (AD D'Andrea, unpubl.), it is possible that the selectivity arises from the ability of the complex to sense and distribute the damaging signals upon ICL.

\section{Acknowledgments}

We thank Simon Boulton for sharing data prior to publication. We thank Clark Chen, Dipanjan Chowdhury, Kalindi Parmar, and all of the members of the D'Andrea laboratory for critical reading of the manuscript. Y.K. is the recipient of the Leukemia and Lymphoma Society Career Development Fellowship. This work was supported by R01DK43389 and R01HL52725.

\section{References}

Adamo A, Collis SI, Adelman CA, Silva N, Horejsi Z, Ward JD, Martinez-Perez E, Boulton SJ, La Volpe A. 2010. Preventing nonhomologous end joining suppresses DNA repair defects of Fanconi Anemia. Mol Cell. 39: 25-35.

Ali AM, Singh TR, Meetei AR. 2009. FANCM-FAAP24 and FANCJ: FA proteins that metabolize DNA. Mutat Res 668: 20-26.

Andreassen PR, D'Andrea AD, Taniguchi T. 2004. ATR couples FANCD2 monoubiquitination to the DNA-damage response. Genes Dev 18: 1958-1963.

Arlt MF, Xu B, Durkin SG, Casper AM, Kastan MB, Glover TW. 2004. BRCA1 is required for common-fragile-site stability via its G2/M checkpoint function. Mol Cell Biol 24: 6701-6709.

Bakker ST, van de Vrugt HJ, Rooimans MA, Oostra AB, Steltenpool J, Delzenne-Goette E, van der Wal A, van der Valk M, Joenje $H$, te Riele $\mathrm{H}$, et al. 2009. Fancm-deficient mice reveal unique features of Fanconi anemia complementation group M. Hum Mol Genet 18: 3484-3495.

Bouwman P, Aly A, Escandell JM, Pieterse M, Bartkova J, van der Gulden H, Hiddingh S, Thanasoula M, Kulkarni A, Yang $\mathrm{Q}$ et al. 2010. 53BP1 loss rescues BRCA1 deficiency and is associated with triple-negative and BRCA-mutated breast cancers. Nat Struct Mol Biol. 17: 688-695

Branzei D, Foiani M. 2008. Regulation of DNA repair throughout the cell cycle. Nat Rev Mol Cell Biol 9: 297-308.

Bridge WL, Vandenberg CJ, Franklin RJ, Hiom K. 2005. The BRIP1 helicase functions independently of BRCA1 in the Fanconi anemia pathway for DNA crosslink repair. Nat Genet 37: 953-957.

Bunting SF, Callen E, Wong N, Chen HT, Polato F, Gunn A, Bothmer A, Feldhahn N, Fernandez-Capetillo O, Cao L et al. 2010. 53BP1 inhibits homologous recombination in Brcaldeficient cells by blocking resection of DNA breaks. Cell 141: $243-254$. 
Cao L, Xu X, Bunting SF, Liu J, Wang RH, Cao LL, Wu JJ, Peng TN, Chen J, Nussenzweig A, et al. 2009. A selective requirement for 53BP1 in the biological response to genomic instability induced by Brcal deficiency. Mol Cell 35: 534541.

Casper AM, Nghiem P, Arlt MF, Glover TW. 2002. ATR regulates fragile site stability. Cell 111: 779-789.

Chan KL, Hickson ID. 2009. On the origins of ultra-fine anaphase bridges. Cell Cycle 8: 3065-3066.

Chan KL, North PS, Hickson ID. 2007. BLM is required for faithful chromosome segregation and its localization defines a class of ultrafine anaphase bridges. EMBO J 26: 3397-3409.

Chan KL, Palmai-Pallag T, Ying S, Hickson ID. 2009. Replication stress induces sister-chromatid bridging at fragile site loci in mitosis. Nat Cell Biol 11: 753-760.

Chen BP, Chan DW, Kobayashi J, Burma S, Asaithamby A, Morotomi-Yano K, Botvinick E, Qin J, Chen DJ. 2005. Cell cycle dependence of DNA-dependent protein kinase phosphorylation in response to DNA double strand breaks. I Biol Chem 280: 14709-14715.

Ciccia A, Ling C, Coulthard R, Yan Z, Xue Y, Meetei AR, Laghmani el $\mathrm{H}$, Joenje $\mathrm{H}, \mathrm{McDonald} \mathrm{N}$, de Winter JP et al. 2007. Identification of FAAP24, a Fanconi anemia core complex protein that interacts with FANCM. Mol Cell 25: 331-343.

Cohn MA, Kowal P, Yang K, Haas W, Huang TT, Gygi SP, D'Andrea AD. 2007. A UAF1-containing multisubunit protein complex regulates the Fanconi anemia pathway. Mol Cell 28: 786-797.

Cole RS. 1973. Repair of DNA containing interstrand crosslinks in Escherichia coli: Sequential excision and recombination. Proc Natl Acad Sci 70: 1064-1068.

Collins NB, Wilson JB, Bush T, Thomashevski A, Roberts KJ, Jones NJ, Kupfer GM. 2009. ATR-dependent phosphorylation of FANCA on serine 1449 after DNA damage is important for FA pathway function. Blood 113: 2181-2190.

Collis SJ, Ciccia A, Deans AJ, Horejsi Z, Martin JS, Maslen SL, Skehel JM, Elledge SJ, West SC, Boulton SJ. 2008. FANCM and FAAP24 function in ATR-mediated checkpoint signaling independently of the Fanconi anemia core complex. Mol Cell 32: $313-324$.

D'Andrea AD, Grompe M. 2003. The Fanconi anaemia/BRCA pathway. Nat Rev Cancer 3: 23-34.

Daniels MJ, Wang Y, Lee M, Venkitaraman AR. 2004. Abnormal cytokinesis in cells deficient in the breast cancer susceptibility protein BRCA2. Science 306: 876-879.

Deans AJ, West SC. 2009. FANCM connects the genome instability disorders Bloom's Syndrome and Fanconi Anemia. Mol Cell 36: 943-953.

Deng Y, Guo X, Ferguson DO, Chang S. 2009. Multiple roles for MRE11 at uncapped telomeres. Nature 460: 914-918.

Difilippantonio S, Gapud E, Wong N, Huang CY, Mahowald G, Chen HT, Kruhlak MJ, Callen E, Livak F, Nussenzweig MC, et al. 2008. 53BP1 facilitates long-range DNA end-joining during V(D)J recombination. Nature 456: 529-533.

Dimitrova N, Chen YC, Spector DL, de Lange T. 2008. 53BP1 promotes non-homologous end joining of telomeres by increasing chromatin mobility. Nature 456: 524-528.

DiTullio RA Jr, Mochan TA, Venere M, Bartkova J, Sehested M, Bartek J, Halazonetis TD. 2002. 53BP1 functions in an ATMdependent checkpoint pathway that is constitutively activated in human cancer. Nat Cell Biol 4: 998-1002.

French CA, Masson JY, Griffin CS, O'Regan P, West SC, Thacker J. 2002. Role of mammalian RAD51L2 (RAD51C) in recombination and genetic stability. J Biol Chem 277: 1932219330.
Fundia A, Gorla N, Larripa I. 1994. Spontaneous chromosome aberrations in Fanconi's anemia patients are located at fragile sites and acute myeloid leukemia breakpoints. Hereditas 120: $47-50$.

Garcia-Higuera I, Taniguchi T, Ganesan S, Meyn MS, Timmers C, Hejna J, Grompe M, D'Andrea AD. 2001. Interaction of the Fanconi anemia proteins and BRCA1 in a common pathway. Mol Cell 7: 249-262.

Gari K, Decaillet C, Delannoy M, Wu L, Constantinou A. 2008a. Remodeling of DNA replication structures by the branch point translocase FANCM. Proc Natl Acad Sci 105: 1610716112.

Gari K, Decaillet C, Stasiak AZ, Stasiak A, Constantinou A. 2008b. The Fanconi anemia protein FANCM can promote branch migration of Holliday junctions and replication forks. Mol Cell 29: 141-148.

Gildemeister OS, Sage JM, Knight KL. 2009. Cellular redistribution of Rad51 in response to DNA damage: Novel role for Rad51C. J Biol Chem 284: 31945-31952.

Gong Z, Kim JE, Leung CC, Glover JN, Chen J. 2010. BACH1/ FANCJ acts with TopBP1 and participates early in DNA replication checkpoint control. Mol Cell 37: 438-446.

Grossmann KF, Ward AM, Matkovic ME, Folias AE, Moses RE. 2001. S. cerevisiae has three pathways for DNA interstrand crosslink repair. Mutat Res 487: 73-83.

Hanada K, Budzowska M, Modesti M, Maas A, Wyman C, Essers J, Kanaar R. 2006. The structure-specific endonuclease Mus81-Eme1 promotes conversion of interstrand DNA crosslinks into double-strands breaks. EMBO J 25: 4921-4932.

Houghtaling S, Newell A, Akkari Y, Taniguchi T, Olson S, Grompe M. 2005. Fancd2 functions in a double strand break repair pathway that is distinct from non-homologous end joining. Hum Mol Genet 14: 3027-3033.

Howlett NG, Taniguchi T, Olson S, Cox B, Waisfisz Q, De DieSmulders C, Persky N, Grompe M, Joenje H, Pals G, et al. 2002. Biallelic inactivation of BRCA2 in Fanconi anemia. Science 297: 606-609.

Howlett NG, Taniguchi T, Durkin SG, D'Andrea AD, Glover TW. 2005. The Fanconi anemia pathway is required for the DNA replication stress response and for the regulation of common fragile site stability. Hum Mol Genet 14: 693-701.

Huang J, Huen MS, Kim H, Leung CC, Glover JN, Yu X, Chen J. 2009. RAD18 transmits DNA damage signalling to elicit homologous recombination repair. Nat Cell Biol 11: 592603.

Huertas P, Cortes-Ledesma F, Sartori AA, Aguilera A, Jackson SP. 2008. CDK targets Sae2 to control DNA-end resection and homologous recombination. Nature 455: 689-692.

Hussain S, Wilson JB, Medhurst AL, Heina J, Witt E, Ananth S, Davies A, Masson JY, Moses R, West SC, et al. 2004. Direct interaction of FANCD2 with BRCA2 in DNA damage response pathways. Hum Mol Genet 13: 1241-1248.

Ip SC, Rass U, Blanco MG, Flynn HR, Skehel JM, West SC. 2008. Identification of Holliday junction resolvases from humans and yeast. Nature 456: 357-361.

Ishiai M, Kitao H, Smogorzewska A, Tomida J, Kinomura A, Uchida E, Saberi A, Kinoshita E, Kinoshita-Kikuta E, Koike T, et al. 2008. FANCI phosphorylation functions as a molecular switch to turn on the Fanconi anemia pathway. Nat Struct Mol Biol 15: 1138-1146.

Karathanasis E, Wilson TE. 2002. Enhancement of Saccharomyces cerevisiae end-joining efficiency by cell growth stage but not by impairment of recombination. Genetics 161: 1015-1027.

Kee Y, Kim JM, D'Andrea AD. 2009. Regulated degradation of FANCM in the Fanconi anemia pathway during mitosis. Genes Dev 23: 555-560. 
Kennedy RD, D'Andrea AD. 2005. The Fanconi Anemia/ BRCA pathway: New faces in the crowd. Genes Dev 19: 2925-2940.

Kim JS, Krasieva TB, Kurumizaka H, Chen DJ, Taylor AM, Yokomori K. 2005. Independent and sequential recruitment of NHEJ and HR factors to DNA damage sites in mammalian cells. J Cell Biol 170: 341-347.

Kim JM, Kee Y, Gurtan A, D'Andrea AD. 2008. Cell cycledependent chromatin loading of the Fanconi anemia core complex by FANCM/FAAP24. Blood 111: 5215-5222.

Kim JM, Parmar K, Huang M, Weinstock DM, Ruit CA, Kutok JL, D'Andrea AD. 2009. Inactivation of murine Usp1 results in genomic instability and a Fanconi anemia phenotype. Dev Cell 16: 314-320.

Knipscheer P, Raschle M, Smogorzewska A, Enoiu M, Ho TV, Scharer OD, Elledge SJ, Walter JC. 2009. The Fanconi anemia pathway promotes replication-dependent DNA interstrand cross-link repair. Science 326: 1698-1701.

Kratz K, Schopf B, Kaden S, Sendoel A, Eberhard R, Lademann C, Cannavo E, Sartori AA, Hengartner MO, Jiricny J. 2010. Deficiency of FANCD2-associated nuclease KIAA1018/ FAN1 sensitizes cells to interstrand crosslinking agents. Cell 142: $77-88$.

Lee SE, Mitchell RA, Cheng A, Hendrickson EA. 1997. Evidence for DNA-PK-dependent and -independent DNA doublestrand break repair pathways in mammalian cells as a function of the cell cycle. Mol Cell Biol 17: 1425-1433.

Levitus M, Waisfisz Q, Godthelp BC, de Vries Y, Hussain S, Wiegant WW, Elghalbzouri-Maghrani E, Steltenpool J, Rooimans MA, Pals G, et al. 2005. The DNA helicase BRIP1 is defective in Fanconi anemia complementation group J. Nat Genet 37: 934-935.

Levran O, Attwooll C, Henry RT, Milton KL, Neveling K, Rio P, Batish SD, Kalb R, Velleuer E, Barral S, et al. 2005. The BRCA1-interacting helicase BRIP1 is deficient in Fanconi anemia. Nat Genet 37: 931-933.

Levy-Lahad E. 2010. Fanconi anemia and breast cancer susceptibility meet again. Nat Genet 42: 368-369.

Li X, Stith CM, Burgers PM, Heyer WD. 2009. PCNA is required for initiation of recombination-associated DNA synthesis by DNA polymerase $\delta$. Mol Cell 36: 704-713.

Ling C, Ishiai M, Ali AM, Medhurst AL, Neveling K, Kalb R, Yan $\mathrm{Z}$, Xue Y, Oostra AB, Auerbach AD, et al. 2007. FAAP100 is essential for activation of the Fanconi anemia-associated DNA damage response pathway. EMBO I 26: 2104-2114.

Litman R, Peng M, Jin Z, Zhang F, Zhang J, Powell S, Andreassen PR, Cantor SB. 2005. BACH1 is critical for homologous recombination and appears to be the Fanconi anemia gene product FANCJ. Cancer Cell 8: 255-265.

Liu Y, West SC. 2008. More complexity to the Bloom's syndrome complex. Genes Dev 22: 2737-2742.

Liu Y, Masson JY, Shah R, O'Regan P, West SC. 2004. RAD51C is required for Holliday junction processing in mammalian cells. Science 303: 243-246.

Liu Y, Tarsounas M, O'Regan P, West SC. 2007. Role of RAD51C and XRCC3 in genetic recombination and DNA repair. J Biol Chem 282: 1973-1979.

Liu T, Ghosal G, Yuan J, Chen J, Huang J. 2010. FAN1 acts with FANC1-FANCD2 to promote DNA interstrand cross-links repair. Science (in press).

Luke-Glaser S, Luke B, Grossi S, Constantinou A. 2010. FANCM regulates DNA chain elongation and is stabilized by S-phase checkpoint signalling. EMBO J 29: 795-805.

Mackay C, Declais AC, Lundin C, Agostinho A, Deans AJ, Macartney TJ, Hofmann K, Gartner A, West SC, Helleday T, et al. 2010. Identification of KIAA1018/FAN1, a DNA repair nuclease recruited to DNA damage by monoubiquitinated FANCD2. Cell 142: 65-76.

McIlwraith MJ, Vaisman A, Liu Y, Fanning E, Woodgate R, West SC. 2005. Human DNA polymerase eta promotes DNA synthesis from strand invasion intermediates of homologous recombination. Mol Cell 20: 783-792.

Meetei AR, Sechi S, Wallisch M, Yang D, Young MK, Joenje H, Hoatlin ME, Wang W. 2003. A multiprotein nuclear complex connects Fanconi anemia and Bloom syndrome. Mol Cell Biol 23: 3417-3426.

Meetei AR, Medhurst AL, Ling C, Xue Y, Singh TR, Bier P, Steltenpool J, Stone S, Dokal I, Mathew CG, et al. 2005. A human ortholog of archaeal DNA repair protein Hef is defective in Fanconi anemia complementation group $\mathbf{M}$. Nat Genet 37: 958-963.

Meindl A, Hellebrand H, Wiek C, Erven V, Wappenschmidt B, Niederacher D, Freund M, Lichtner P, Hartmann L, Schaal H et al. 2010. Germline mutations in breast and ovarian cancer pedigrees establish RAD51C as a human cancer susceptibility gene. Nat Genet. 42: 410-414

Mekeel KL, Tang W, Kachnic LA, Luo CM, DeFrank JS, Powell SN. 1997. Inactivation of p53 results in high rates of homologous recombination. Oncogene 14: 1847-1857.

Moldovan GL, D'Andrea AD. 2009. How the fanconi anemia pathway guards the genome. Annu Rev Genet 43: 223-249.

Moldovan GL, Madhavan MV, Mirchandani KD, McCaffrey RM, Vinciguerra P, D'Andrea AD. 2010. DNA polymerase POLN participates in cross-link repair and homologous recombination. Mol Cell Biol 30: 1088-1096.

Mosedale G, Niedzwiedz W, Alpi A, Perrina F, Pereira-Leal JB, Johnson M, Langevin F, Pace P, Patel KJ. 2005. The vertebrate Hef ortholog is a component of the Fanconi anemia tumorsuppressor pathway. Nat Struct Mol Biol 12: 763-771.

Moynahan ME, Cui TY, Jasin M. 2001a. Homology-directed dna repair, mitomycin-c resistance, and chromosome stability is restored with correction of a Brcal mutation. Cancer Res 61: 4842-4850.

Moynahan ME, Pierce AJ, Jasin M. 2001b. BRCA2 is required for homology-directed repair of chromosomal breaks. Mol Cell 7: 263-272.

Muzzini DM, Plevani P, Boulton SJ, Cassata G, Marini F. 2008. Caenorhabditis elegans POLQ-1 and HEL-308 function in two distinct DNA interstrand cross-link repair pathways. DNA Repair (Amst) 7: 941-950.

Naim V, Rosselli F. 2009a. The FANC pathway and BLM collaborate during mitosis to prevent micro-nucleation and chromosome abnormalities. Nat Cell Biol 11: 761-768.

Naim V, Rosselli F. 2009b. The FANC pathway and mitosis: A replication legacy. Cell Cycle 8: 2907-2911.

Nakanishi K, Taniguchi T, Ranganathan V, New HV, Moreau LA, Stotsky M, Mathew CG, Kastan MB, Weaver DT, D'Andrea AD. 2002. Interaction of FANCD2 and NBS1 in the DNA damage response. Nat Cell Biol 4: 913-920.

Nakanishi K, Yang YG, Pierce AJ, Taniguchi T, Digweed M, D'Andrea AD, Wang ZQ, Jasin M. 2005. Human Fanconi anemia monoubiquitination pathway promotes homologous DNA repair. Proc Natl Acad Sci 102: 1110-1115.

Newell AE, Akkari YM, Torimaru Y, Rosenthal A, Reifsteck CA, Cox B, Grompe M, Olson SB. 2004. Interstrand crosslink-induced radials form between non-homologous chromosomes, but are absent in sex chromosomes. DNA Repair (Amst) 3: 535-542.

Niedernhofer LJ, Odijk H, Budzowska M, van Drunen E, Maas A, Theil AF, de Wit J, Jaspers NG, Beverloo HB, Hoeijmakers $\mathrm{JH}$, et al. 2004. The structure-specific endonuclease Ercc1-Xpf is required to resolve DNA interstrand cross-link-induced double-strand breaks. Mol Cell Biol 24: 5776-5787. 
Niedernhofer LJ, Lalai AS, Hoeijmakers JH. 2005. Fanconi anemia (cross)linked to DNA repair. Cell 123: 1191-1198.

Niedzwiedz W, Mosedale G, Johnson M, Ong CY, Pace P, Patel KJ. 2004. The Fanconi anaemia gene FANCC promotes homologous recombination and error-prone DNA repair. Mol Cell 15: 607-620.

Nijman SM, Huang TT, Dirac AM, Brummelkamp TR, Kerkhoven RM, D'Andrea AD, Bernards R. 2005. The deubiquitinating enzyme USP1 regulates the Fanconi anemia pathway. Mol Cell 17: 331-339.

Oestergaard VH, Langevin F, Kuiken HJ, Pace P, Niedzwiedz W, Simpson LJ, Ohzeki M, Takata M, Sale JE, Patel KJ. 2007. Deubiquitination of FANCD2 is required for DNA crosslink repair. Mol Cell 28: 798-809.

Pace P, Mosedale G, Hodskinson M, Rosado IV, Sivasubramaniam M, Patel KJ. 2010. Ku70 corrupts DNA repair in the absence of the Fanconi anemia pathway. Science.329: 219-223.

Paull TT, Cortez D, Bowers B, Elledge SJ, Gellert M. 2001. Direct DNA binding by Brca1. Proc Natl Acad Sci 98: 60866091.

Peng M, Litman R, Xie J, Sharma S, Brosh RM Jr, Cantor SB. 2007. The FANCJ/MutL $\alpha$ interaction is required for correction of the cross-link response in FA-J cells. EMBO $J \mathbf{2 6}$ 3238-3249.

Pichierri P, Rosselli F. 2004. The DNA crosslink-induced S-phase checkpoint depends on ATR-CHK1 and ATR-NBS1FANCD2 pathways. EMBO I 23: 1178-1187.

Pierce AJ, Hu P, Han M, Ellis N, Jasin M. 2001. Ku DNA endbinding protein modulates homologous repair of doublestrand breaks in mammalian cells. Genes Dev 15: 3237-3242.

Porfirio B, Smeets D, Beckers L, Caporossi D, Tedeschi B, Vernole P, Joenje H, Nicoletti B, Dallapiccola B. 1991. Fragile sites and chromosome instability: The distribution of breaks induced by cis-diamine-dichloro-platinum (II) in Fanconi anemia lymphocyte cultures. Hum Genet 86: 256-260.

Postow L, Ghenoiu C, Woo EM, Krutchinsky AN, Chait BT, Funabiki H. 2008. Ku80 removal from DNA through double strand break-induced ubiquitylation. I Cell Biol 182: 467479.

Richardson C, Elliott B, Jasin M. 1999. Chromosomal doublestrand breaks introduced in mammalian cells by expression of I-Sce I endonuclease. Methods Mol Biol 113: 453-463.

Rodrigue A, Lafrance M, Gauthier MC, McDonald D, Hendzel M, West SC, Jasin M, Masson JY. 2006. Interplay between human DNA repair proteins at a unique double-strand break in vivo. $E M B O$ I 25: 222-231.

Saberi A, Hochegger H, Szuts D, Lan L, Yasui A, Sale JE, Taniguchi Y, Murakawa Y, Zeng W, Yokomori K, et al. 2007. RAD18 and poly(ADP-ribose) polymerase independently suppress the access of nonhomologous end joining to double-strand breaks and facilitate homologous recombination-mediated repair. Mol Cell Biol 27: 2562-2571.

Sartori AA, Lukas C, Coates J, Mistrik M, Fu S, Bartek J, Baer R, Lukas J, Jackson SP. 2007. Human CtIP promotes DNA end resection. Nature 450: 509-514.

Schwab RA, Blackford AN, Niedzwiedz W. 2010. ATR activation and replication fork restart are defective in FANCMdeficient cells. $E M B O$ J 29: 806-818.

Singh TR, Bakker ST, Agarwal S, Jansen M, Grassman E, Godthelp BC, Ali AM, Du CH, Rooimans MA, Fan Q, et al. 2009. Impaired FANCD2 monoubiquitination and hypersensitivity to camptothecin uniquely characterize Fanconi anemia complementation group M. Blood 114: 174-180.

Singh TR, Saro D, Ali AM, Zheng XF, Du CH, Killen MW, Sachpatzidis A, Wahengbam K, Pierce AJ, Xiong Y, et al. 2010. MHF1-MHF2, a histone-fold-containing protein com- plex, participates in the Fanconi anemia pathway via FANCM. Mol Cell 37: 879-886.

Smogorzewska A, Matsuoka S, Vinciguerra P, McDonald ER III, Hurov KE, Luo J, Ballif BA, Gygi SP, Hofmann K, D'Andrea $\mathrm{AD}$, et al. 2007. Identification of the FANCI protein, a monoubiquitinated FANCD2 paralog required for DNA repair. Cell 129: 289-301.

Smogorzewska A, Desetty R, Saito TT, Schlabach M, Lach FP, Sowa ME, Clark AB, Kunkel TA, Harper JW, Colaiacovo MP, et al. 2010. A genetic screen identifies FAN1, a Fanconi Anemia-associated nuclease necessary for DNA interstrand crosslink repair. Mol Cell 39: 36-47.

Sommers JA, Rawtani N, Gupta R, Bugreev DV, Mazin AV, Cantor SB, Brosh RM Jr. 2009. FANCJ uses its motor ATPase to destabilize protein-DNA complexes, unwind triplexes, and inhibit RAD51 strand exchange. J Biol Chem 284: 75057517.

Strathdee CA, Gavish H, Shannon WR, Buchwald M. 1992. Cloning of cDNAs for Fanconi's anaemia by functional complementation. Nature 358: 434.

Sun W, Nandi S, Osman F, Ahn JS, Jakovleska J, Lorenz A, Whitby MC. 2008. The FANCM ortholog Fmll promotes recombination at stalled replication forks and limits crossing over during DNA double-strand break repair. Mol Cell 32: $118-128$.

Sy SM, Huen MS, Chen J. 2009. PALB2 is an integral component of the BRCA complex required for homologous recombination repair. Proc Natl Acad Sci 106: 7155-7160.

Takata M, Sasaki MS, Sonoda E, Morrison C, Hashimoto M, Utsumi H, Yamaguchi-Iwai Y, Shinohara A, Takeda S. 1998. Homologous recombination and non-homologous endjoining pathways of DNA double-strand break repair have overlapping roles in the maintenance of chromosomal integrity in vertebrate cells. EMBO J 17: 5497-5508.

Takata M, Sasaki MS, Sonoda E, Fukushima T, Morrison C, Albala JS, Swagemakers SM, Kanaar R, Thompson LH, Takeda S. 2000. The Rad51 paralog Rad51B promotes homologous recombinational repair. Mol Cell Biol 20: 6476-6482.

Takata M, Sasaki MS, Tachiiri S, Fukushima T, Sonoda E, Schild D, Thompson LH, Takeda S. 2001. Chromosome instability and defective recombinational repair in knockout mutants of the five Rad51 paralogs. Mol Cell Biol 21: 2858-2866.

Taniguchi T, Garcia-Higuera I, Andreassen PR, Gregory RC, Grompe M, D'Andrea AD. 2002. S-phase-specific interaction of the Fanconi anemia protein, FANCD2, with BRCA1 and RAD51. Blood 100: 2414-2420.

Thompson LH, Schild D. 2001. Homologous recombinational repair of DNA ensures mammalian chromosome stability. Mutat Res 477: 131-153.

Turnbull C, Rahman N. 2008. Genetic predisposition to breast cancer: Past, present, and future. Annu Rev Genomics Hum Genet 9: 321-345.

Vaz F, Hanenberg H, Schuster B, Barker K, Wiek C, Erven V, Neveling K, Endt D, Kesterton I, Autore F et al. 2010. Mutation of the RAD51C gene in a Fanconi anemia-like disorder. Nat Genet 42: 406-409.

Wang W. 2007. Emergence of a DNA-damage response network consisting of Fanconi anaemia and BRCA proteins. Nat Rev Genet 8: 735-748.

Wang X, Andreassen PR, D'Andrea AD. 2004. Functional interaction of monoubiquitinated FANCD2 and BRCA2/ FANCD1 in chromatin. Mol Cell Biol 24: 5850-5862.

Wang X, Kennedy RD, Ray K, Stuckert P, Ellenberger T, D'Andrea AD. 2007. Chk1-mediated phosphorylation of FANCE is required for the Fanconi anemia/BRCA pathway. Mol Cell Biol 27: 3098-3108. 
Ward JD, Muzzini DM, Petalcorin MI, Martinez-Perez E, Martin JS, Plevani P, Cassata G, Marini F, Boulton SJ. 2010. Overlapping mechanisms promote postsynaptic RAD-51 filament disassembly during meiotic double-strand break repair. Mol Cell 37: 259-272.

Whitby MC. 2010. The FANCM family of DNA helicases/ translocases. DNA Repair (Amst) 9: 224-236.

Wilson JB, Yamamoto K, Marriott AS, Hussain S, Sung P, Hoatlin ME, Mathew CG, Takata M, Thompson LH, Kupfer GM, et al. 2008. FANCG promotes formation of a newly identified protein complex containing BRCA2, FANCD2 and XRCC3. Oncogene 27: 3641-3652.

Wooster R, Weber BL. 2003. Breast and ovarian cancer. N Engl J Med 348: 2339-2347.

Xia B, Sheng Q, Nakanishi K, Ohashi A, Wu J, Christ N, Liu X, Jasin M, Couch FJ, Livingston DM. 2006. Control of BRCA2 cellular and clinical functions by a nuclear partner, PALB2. Mol Cell 22: 719-729.

Xia B, Dorsman JC, Ameziane N, de Vries Y, Rooimans MA, Sheng Q, Pals G, Errami A, Gluckman E, Llera J, et al. 2007. Fanconi anemia is associated with a defect in the BRCA2 partner PALB2. Nat Genet 39: 159-161.

Xue Y, Li Y, Guo R, Ling C, Wang W. 2008. FANCM of the Fanconi anemia core complex is required for both monoubiquitination and DNA repair. Hum Mol Genet 17: 1641-1652.

Yamamoto K, Hirano S, Ishiai $M$, Morishima K, Kitao $\mathrm{H}$, Namikoshi K, Kimura M, Matsushita N, Arakawa H, Buerstedde JM, et al. 2005. Fanconi anemia protein FANCD2 promotes immunoglobulin gene conversion and DNA repair through a mechanism related to homologous recombination. Mol Cell Biol 25: 34-43.

Yan Z, Delannoy M, Ling C, Daee D, Osman F, Muniandy PA, Shen $\mathrm{X}$, Oostra AB, Du H, Steltenpool J, et al. 2010. A histone-fold complex and FANCM form a conserved DNAremodeling complex to maintain genome stability. Mol Cell 37: 865-878.

Youds JL, Barber LJ, Ward JD, Collis SJ, O'Neil NJ, Boulton SJ, Rose AM. 2008. DOG-1 is the Caenorhabditis elegans BRIP1/FANCJ homologue and functions in interstrand cross-link repair. Mol Cell Biol 28: 1470-1479.

Yu X, Chen J. 2004. DNA damage-induced cell cycle checkpoint control requires CtIP, a phosphorylation-dependent binding partner of BRCA1 C-terminal domains. Mol Cell Biol 24: 9478-9486.

Yun MH, Hiom K. 2009. CtIP-BRCA1 modulates the choice of DNA double-strand-break repair pathway throughout the cell cycle. Nature 459: 460-463.

Zha S, Boboila C, Alt FW. 2009. Mre11: Roles in DNA repair beyond homologous recombination. Nat Struct Mol Biol 16: 798-800.

Zhang N, Liu X, Li L, Legerski R. 2007. Double-strand breaks induce homologous recombinational repair of interstrand cross-links via cooperation of MSH2, ERCC1-XPF, REV3, and the Fanconi anemia pathway. DNA Repair (Amst) 6: 1670-1678.

Zhang F, Fan Q, Ren K, Andreassen PR. 2009a. PALB2 functionally connects the breast cancer susceptibility proteins BRCA1 and BRCA2. Mol Cancer Res 7: 1110-1118.

Zhang F, Ma J, Wu J, Ye L, Cai H, Xia B, Yu X. 2009b. PALB2 links BRCA1 and BRCA2 in the DNA-damage response. Curr Biol 19: 524-529.

Zhi G, Wilson JB, Chen X, Krause DS, Xiao Y, Jones NJ, Kupfer GM. 2009. Fanconi anemia complementation group FANCD2 protein serine 331 phosphorylation is important for fanconi anemia pathway function and BRCA2 interaction. Cancer Res 69: 8775-8783. 


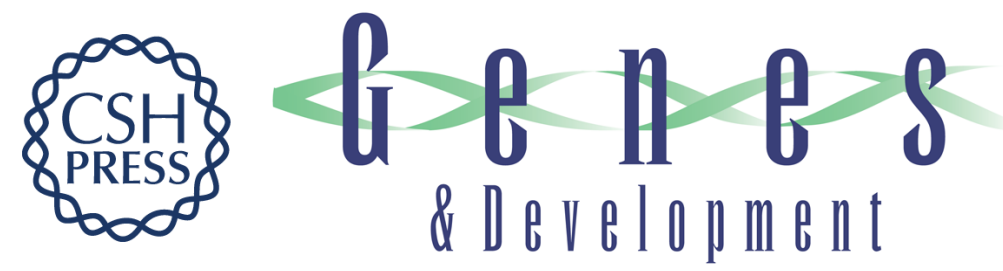

\section{Expanded roles of the Fanconi anemia pathway in preserving genomic stability}

Younghoon Kee and Alan D. D'Andrea

Genes Dev. 2010, 24:

Access the most recent version at doi:10.1101/gad.1955310

References This article cites 132 articles, 44 of which can be accessed free at: http://genesdev.cshlp.org/content/24/16/1680.full.html\#ref-list-1

License

Email Alerting

Receive free email alerts when new articles cite this article - sign up in the box at the top Service right corner of the article or click here.

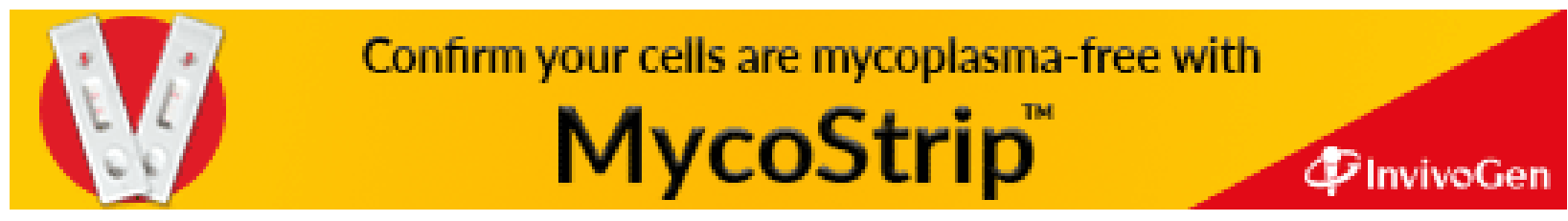

